\title{
Nombres mágicos, nombres bárbaros, epítetos divinos en el himno a Afrodita en el PGM IV 2891-2941
}

Marcela Alejandra Ristorto

Universidad Nacional de Rosario, Argentina

mristor@gmail.com

Recibido: 10/04/2018. Aceptado: 21/05/2018.

\begin{abstract}
Resumen
En los Papyri Graecae Magicae de Preisendanz-Henrich se encuentra un material hímnico cuyo principal rasgo formal es la cuantiosa cantidad de epítetos tradicionales pero también de 'nombres mágicos' que llevan sobre sí el poder mismo de la divinidad, de 'nombres bárbaros', es decir, los nombres que otros pueblos daban a esa misma deidad, incluyendo así elementos egipcios, mesopotámicos y hebreos. Esta proliferación de nombres remite a la realidad del sincretismo religioso helenístico. Sin embargo también puede verse que los himnos mágicos evidencian continuidades con la tradición hímnica griega. Este trabajo se propone establecer las relaciones de continuidad y/o ruptura entre el himno mágico a Afrodita (PGM IV 2902-2939) con la himnodia griega. Para ello, se analiza tanto la estructura hímnica como los contextos probables de ejecución.
\end{abstract}

\section{Magical names, barbarian names, divine epithets in the hymn to Aphrodite in the PGM IV 2891-2941}

\begin{abstract}
In the Papyri Graecae Magicae of Preisendanz-Henrich there are hymns whose main formal feature is the large number of traditional epithets but also of 'magic names' that bear on themselves the power of the deity, of 'barbarian names', is to say, the names that other people gave to that same deity, in this way the hymns include Egyptian, Mesopotamian and Hebrew elements. This proliferation of names refers to the reality of Hellenistic religious syncretism. However, it can also be seen that the magic hymns show continuities with the Greek hymn tradition. This work aims to establish relations of continuity and / or rupture between the magic hymn to Aphrodite (PGM IV 2902-2939) with the Greek hymnody. To do this, we analyze both the hymnic structure and the likely contexts of execution.
\end{abstract}

\section{Palabras clave}

himnos

magia

religión griega

\section{Keywords \\ Hymns \\ Magic \\ Greek religión}


1. Una versión más extensa y en inglés, "Love Spell and Hymn to Aphrodite in PGMIV (2891-2941)", ha sido leída en la Conference Cultural Plurality in Ancient Magical Texts and Practices, Heidelberg, 2014. Esta versión será publicada en Proceedings 'Cultural Plurality in Ancient Magical texts and practices' (en prensa). Asimismo debo señalar que este trabajo es parte de una investigación mayor, en la que se examinan los himnos y las invocaciones en textos mágicos dirigidos a Artemis, a Hécate, a Perséfone y a Afrodita o Mirra. El objetivo es estudiar cómo se configura una deidad femenina cómo se configura una deidad femenina
suprema, de características tanto ctónicas como celestes (específicamente lunar). En este artículo me centro en el Himno a Afrodita (PGM IV 2912-2939) porque considero que puede ser ilustrativo para establecer las semejanzas y/o diferencias existentes entre los himnos ejecutados en el marco de la religión tradicional y los mágicos, dado que en el corpus hímnico conservado, desde Homero en adelante, se encuentran diveresta deidad, que pueden ser cotejadas con el himno del Papiro Mágico IV.

2. La relación entre magia y religión es un problema ampliamente discutido por los especialistas, ver entre otros Versnel (1991), Graf (1991; 2002), Betz (1991), Iles Johnston (2002). 3. Pl. Lg. 909 b; R. 364 b.

4. En el presente trabajo las citas del himno corresponden a la edición de Preisendanz et al. (1928); las traducciones son las de la edicion de J. L. Calvo Martínez; M. D. Sánchez Romero (1986).
5. Esta estructura tripartita incluye tres

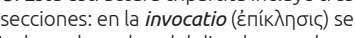
incluye el nombre del dios, los nombres cultuales y los epítetos; en la eulogia

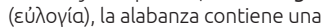
descripción del dios, de los lugares que frecuenta y sus actividades o una narración de alguna hazaña divina. Finalmente en la petición o plegaria (Eủxń) se solicita la ayuda del dios y se agradece la protección recibida. Cfr. Janko (1981:9-24); Strauss Clay (1997:489507) y Furley-Bremer (2001: I 1-64).
En los Papyri Graecae Magicae de Preisendanz-Henrich se encuentra un material hímnico cuyo principal rasgo formal es la cuantiosa cantidad de epítetos tradicionales de la divinidad pero también de 'nombres mágicos' que llevan sobre sí el poder mismo de la divinidad y de 'nombres bárbaros', que constituían el modo en que los no griegos designaban al dios, incluyendo así elementos egipcios, mesopotámicos y hebreos. Este trabajo se propone como objetivo examinar el Himno a Afrodita en el PGM IV 2902-2939), ${ }^{\top}$ interrogándonos acerca de si realmente existen diferencias entre los himnos mágicos y los himnos cultuales, más allá de esta proliferación de nombres divinos. Este interrogante se inserta en las controversias sobre la diferencia entre la magia y la religión. ${ }^{2}$ Sin embargo, estos debates obedecen más a la percepción moderna, ya que para los griegos un mago no sólo enuncia sortilegios, sino también

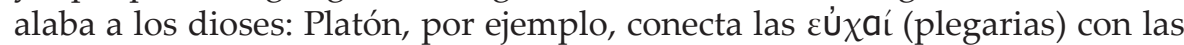

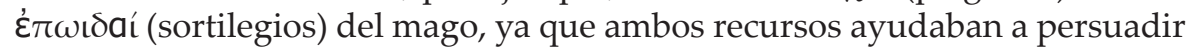
$(\pi \varepsilon \dot{\theta} \theta \varepsilon \iota v)$ a los dioses. ${ }^{3}$

El himno a Afrodita es ejecutado en el marco de un ritual mágico denominado 'práctica de sometimiento' (PMG IV 2891). En primer lugar se describe la confección de una ofrenda a la estrella de Afrodita, seguido por los elementos compulsivos del rito: la fórmula coactiva y el himno. Si bien la eficacia de todo conjuro mágico depende de la conjunción entre la praxis y el logos, analizaremos - por el objetivo de nuestro trabajo- directamente la fórmula coercitiva (2898 ss.):

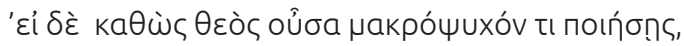

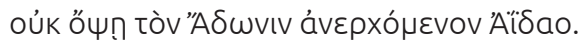

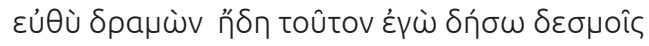

2900

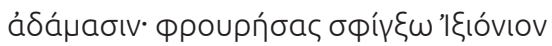

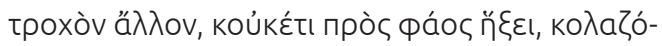

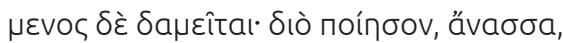

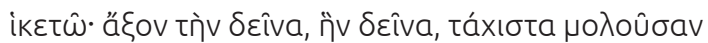

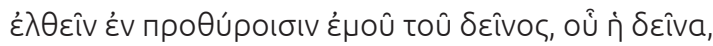

Фı

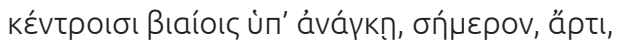

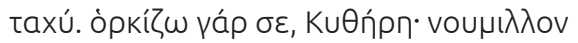

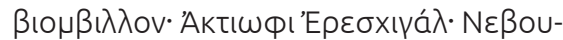

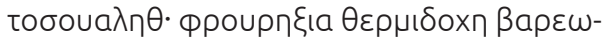
$\mathrm{V} \eta^{\prime} .4$

2905

Si tú, como diosa que eres, actúas lentamente, no verás a Adonis subir de Hades. Correré yo con toda presteza y lo ataré con fuertes ligaduras; después de hacer guardia apretaré otra rueda ixionia y en modo alguno vendrá a la luz, sino que, dominado de esta forma, estará sumiso. Por ello, diosa, actúa, te lo suplico: tráeme a fulana, hija de mengana, que se apresure, que venga a las puertas de la casa donde yo vivo, fulano, hijo de mengana, por amor y para compartir mi lecho, empujada por un aguijón, bajo la necesidad de violentos acicates, hoy, ahora mismo, pronto. Porque te conjuro a ti, Citerea, noumillon biombillon, Actiofi Eresquigal, Nebutosualet, phrourēxia thermidochē bareōnē

Cabe señalar que la fórmula coercitiva posee una estructura hímnica, ya que tiene dos de las secciones características de los himnos que se ejecutaban en

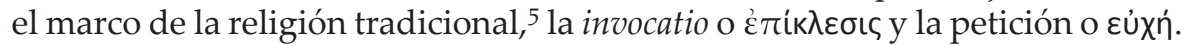
En la invocatio el mago junto al epíteto tradicional, KuӨńpn [Citerea], emplea voces magicae, es decir, palabras de significado ininteligible, frecuentemente 
plagadas de aliteraciones, de origen incierto, y que generalmente estaban combinadas en extensas listas. Como sostiene Versnell (2002:115-116), muchas de estas voces no tenían un significado referencial frente a los 'nombres bárbaros' ${ }^{6}$ que eran considerados nombres divinos auténticos. Se pensaba que ambos recursos eran sumamente eficaces, ya que pertenecían al lenguaje secreto de los dioses. ${ }^{7}$ Así en la fórmula coercitiva el mago recurre a tres 'nombres bárbaros', es decir, nombres secretos de deidades subterráneas extranjeras asimi-

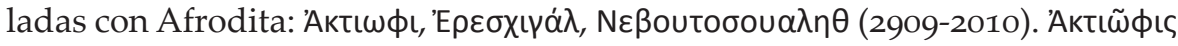
es generalmente un epíteto de diferentes diosas, Hécate, Selene y Afrodita, entre otras ( $P G M$ IV 2473, 2484, 2601, 2664, 2749, 2913, etc.); pero en el PGM IV 2469 es el nombre de una deidad. Cabe señalar en relación a $N \varepsilon \beta$ $\varepsilon$ tooou $\alpha \lambda \eta \theta$ (2909-10) que este nombre en los papiros mágicos aparece solamente en listados de 'nombres bárbaros' y de voces magicae. Según Brashear (1995:3436) esta deidad ha sido interpretada "as Babylonian, Nebu being a Babylonian deity, whilst others had suggested it is Egyptian". Sin embargo, Tardieu (2013:229) afirma que $N \varepsilon \beta$ outooou $\alpha \lambda \eta \theta$ podría actuar como una suerte de epiclesis de

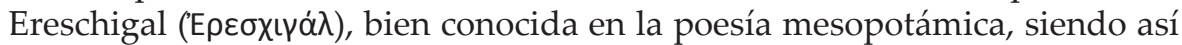
Afrodita interpretada como la soberana del reino de los muertos, una nueva suerte de Perséfone. Por otro lado, Merkelbach (1990-1991:113) afirma que Afrodita es sólo una de las muchas formas que Hécate podría tomar. Y declara

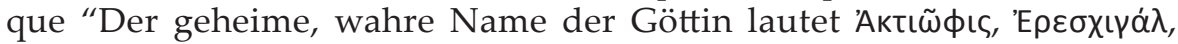
$\mathrm{N} \varepsilon \beta$ ßoutoбov $\lambda \lambda \eta \theta^{\prime}$. Esto podría estar relacionado con una gema mágica que fue

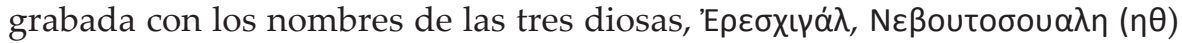
$v \varepsilon \lambda \chi \varepsilon\llcorner\omega \theta \iota$, una notable representación de la triple Hécate (Delatte; Derchain, 1964:193). Es decir, como plantea Tardieu (2013:229) el acto de intimidar a la diosa se hace en lenguaje ininteligible, por medio del encantamiento de este poderoso lenguaje mágico.

El mago adapta las formas propias de la himnodia a sus necesidades; de este modo una expresión de desafío, una amenaza que busca intimidar a Afrodita inicia la fórmula. Sin embargo, en esta invocatio-amenaza encontramos referencias mitológicas, propias más bien de la eulogia que de la invocatio. En primer lugar, se nombra al amante que la diosa debe compartir con Perséfone: Adonis. El joven muerto en una cacería, es el único de los semidioses que cada año puede volver del reino de Hades ( $c f r$. Theoc. 15.86, 100-105, 136-144). Y la mención de la 'rueda ixionia' (cfr. Pi. P. 4.214 ss.), remite al mito de Iunx, la joven hechicera, hija de Peitho o de la ninfa Eco, que logró con sus sortilegios seducir a Zeus o que éste se uniese con Io. Hera se vengó transformándola en el ave del mismo nombre, destinada a servir a empresas amorosas (cfr. sch. Pi. N. 4.156a, Suidas s.v. Iunx.). Por otra parte, la referencia a la 'rueda ixionia' evidencia el sincretismo religioso, ya que este instrumento de la magia erótica en la tradición arcaica y clásica estaba vinculado con Afrodita, mientras que en la antigüedad tardía es el instrumento mágico de Hécate, utilizado por los teúrgos para invocar a los dioses (cfr. Karivieri, 2010:245).

Como señala Graf (1991:189), la configuración de este sortilegio mágico es importante, ya que la estructura es funcional. En la invocatio se llama la atención de la divinidad y se le exige que venga y que cumpla los deseos del enamorado. Luego sigue la petición y finaliza con otra invocación. Podría pensarse que el deseo es tan urgente que se expresa inmediatamente después de haber amenazado a la diosa.

Luego de quemada la ofrenda y recitada la fórmula de coerción, el mago canta un himno a Afrodita (PGM 2915-2941) que posee una estructura tripartita que concuerda con la usual de un himno cultual.
6. Al utilizar la denominación 'nombres bárbaros' seguimos a Tardieu (2013:225-231, esp. 231), quien utiliza la expresión para referirse a palabras en otro idioma, a nombres secretos de deidades extranjeras.

7. Para 'nombres bárbaros' y voces magicae como nombres secretos de deidades, véanse entre otros Simon (1980:503-520); Graf (1991:192); cfr. PGMIV 1266, XII 240 (= XIII 763). 


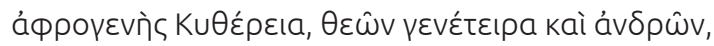

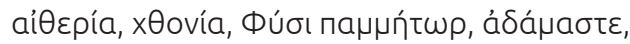

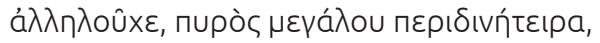

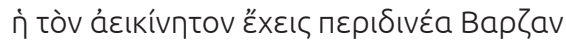

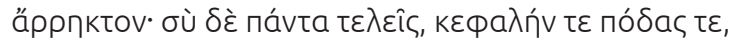

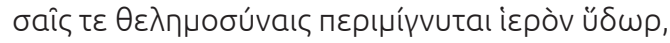

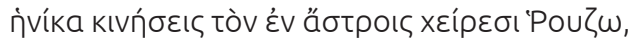

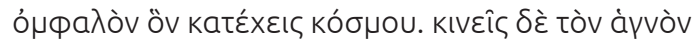

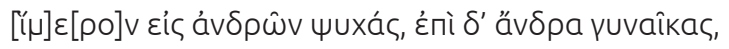

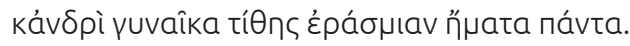

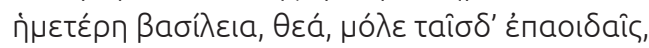

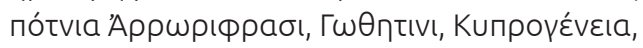

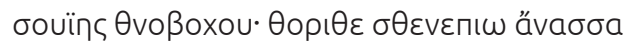

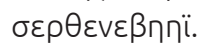

Nacida de la espuma, Citerea, madre de dioses y de hombres, etérea, terrenal, Naturaleza Madre de todo, indomable, la que todo lo mantienes unido, tú que haces girar el gran fuego, tú que mantienes indisoluble a Barza que se mueve eternamente en giros. Tú lo haces todo, cabeza y pies, y por tus decisiones el agua sagrada se mezcla en todas partes cuando con tus manos mueves a la que está en las estrellas, a Ruzo, ombligo del cosmos que tú dominas. Tú empujas el sagrado deseo hacia las almas de los hombres y de las mujeres hacia el hombre; y haces a la mujer deseada por el hombre durante todos sus días. Reina nuestra, diosa, acude a estas invocaciones mágicas, señora Arrōriphrasi, Gōthētini, nacida en Chipre, souïēs thnobochou, thorithe sthenepiō soberana, serthenebēēï.

En la invocatio encontramos una enumeración meticulosa de los títulos cultuales, que tenían en cuenta todos los aspectos relevantes de su persona divina. Cabe señalar que, si bien la extensa enumeracion de epítetos y epíclesis es una característica de la himnodia de la antigüedad tardía, en el caso de los himnos mágicos este listado sirve para demostrar el amplio conocimiento del mago, obtenido gracias a su relación cercana con la deidad. Por otra parte, se consideraba que esta lista de nombres procuraba placer a los dioses, 'obligandolos' así a colaborabar con alegría con la ejecución del sortilegio (cfr. Graf, 1991:192). Al tiempo que el mago emplea los epítetos tradicionales

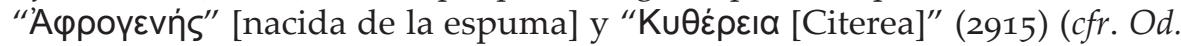
18.193; hVen. 1.1; Hes. Th.196 s., 934, 1008, OH 1.11.), asimismo se la llama

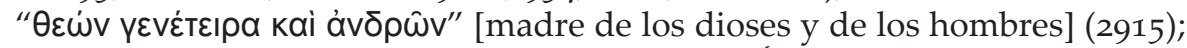

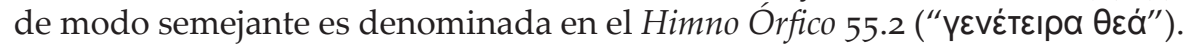
Este epíteto es utilizado también para invocar a deidades vinculadas con lo subterráneo, así en el Himno Órfico 3 sirve a la Noche y en el Himno Órfico 29 a las Euménides. La asociación de Afrodita con la noche puede estar relacionada con la naturaleza nocturna de los placeres sensuales. Pero, por otra parte, la

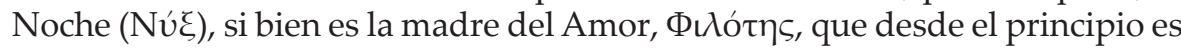
parte de los asistentes de la diosa (Hes. Th. 224), es una deidad vinculada a lo

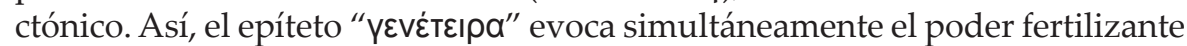
de la deidad y su lado sombrío, su vínculo con el Inframundo. Sin embargo, como señala Pirenne-Delforge (1994:443), el lado oscuro de las prerrogativas de Afrodita reafirma su protección de manifestaciones vitales, entre las que se encuentra la muerte.

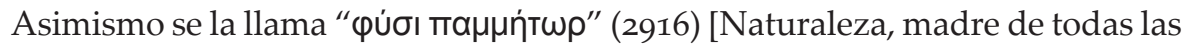
cosas], lo que remite al hHom 30, donde el aedo invoca a Gea con este epíteto. El autor del himno bien puede referirse a la Venus Physica de Lucrecio, en de 
Rerum Natura, donde la diosa se representa como la Madre Naturaleza, (rerum natura creatrix 1.629, 2.1117, 5.1362). En el proemio del poema de Lucrecio, Venus se presenta como la fuerza vivificadora de la naturaleza, ya que gracias al deseo que incita produce el nacimiento y el crecimiento a todo lo que existe. Pero este nombre también podría referirse al título Mńтn $\rho \varepsilon \omega \hat{\omega}$ [Madre de los Dioses], que nos permite postular la influencia de Isis, como Diosa Madre, ya que según Dunand (2010:41) Isis es "avant tout ... une mère divine". Además, en himnos demóticos a la deidad se la llama 'Madre de los Dioses' porque es la madre de Horus pero también porque ella alimenta a todos los dioses y hombres. Isis es a la vez una diosa de la fertilidad y el amor y la sexualidad, por lo que es natural que la deidad se fusionara con la frigia Madre de los Dioses, con Afrodita y con Ishtar de la religión mesopotámica (Witt, 1971:131). Es posible también, como señala Tardieu (2013:230), que el mago, al caracterizar a Afrodita como "naturaleza, madre de todas las cosas", esté atribuyéndole también los rasgos de Anāhitā irania, diosa de la fecundidad. Este proceso de asimilación de Afrodita con todas estas diosas orientales pone en evidencia que la naturaleza y el ámbito de acción de Afrodita en la época de composición y circulación de los papiros mágicos eran diferentes a los de la diosa en la religión tradicional griega, tal como es presentada en Homero en adelante. En los PGM la presentación de Afrodita está marcada por el proceso de construcción de una deidad femenina suprema. Para ello, los autores de los himnos mágicos se de facetas o áreas de acción de las diferentes diosas. Aquí, por ejemplo, son subrayados no solo el erotismo de Afrodita sino también su poder cósmico. Es por esto que el mago nombra a esta deidad a través de sus atributos vinculados con la fertilidad y especialmente con su función cosmológica.

Afrodita es invocada además como " $\alpha i \theta \varepsilon \varepsilon^{\prime} \alpha^{\prime \prime} 8$ [etérea] y " $\chi \theta$ oví́ $\alpha$ " [terrenal] (2916). En realidad, es el segundo epíteto el que es importante, puesto que era empleado para invocar a Hécate, como por ejemplo, en Aristófanes en los frs. 500 y 501 y en Teócrito en el Idilio 2. También el Himno Órfico 4o Deo y Perséfone son invocadas con este título cultual, mientras que en el Himno 71 solamente Perséfone, como esposa de Hades, es llamada "vú $\mu \phi \eta v \chi \emptyset o v i ́ \alpha v^{\prime} .{ }^{9}$ Asimismo en esta colección hímnica, la Madre Frigia que habita en el monte Ida o en el Tmolo es alabada como " $\chi \theta$ oví $\alpha$ " (49). Así el mago emplea un epíteto que no era frecuentemente usado para referirse a Afrodita, ya que alude a diosas vinculadas al Inframundo. ${ }^{10}$

Una posible explicación para el gran número de epítetos que Afrodita recibe es que en la invocatio de este himno mágico prevalece el dispositivo retórico de la enumeración, para reforzar el carácter encantatorio del poema (Pocceti, 1991:191-192). Esta lista de epítetos no pretende ser exhaustiva, sino que tiene como objetivo lograr una eficiencia absoluta. El mago muestra su enorme conocimiento del lenguaje secreto de los dioses, conocimiento que explica y justifica su enorme poder (Gordon, 1999:242). Esta lista de epítetos, que es típica de los himnos mágicos, puede considerarse una característica estilística que evidencia la influencia de los himnos órficos y de los egipcios. Por otra parte, el uso de epítetos comúnmente aplicados a Hécate, Gea, la Noche o las Euménides evidencia la nueva naturaleza de Afrodita en los $P G M$, puesto que estos títulos refieren a deidades vinculadas al mundo subterráneo. Como señala Tardieu (2013:230-231) en la naturaleza de la diosa se superponen aspectos de la Afrodita griega y la concepción de una Afrodita sincrética propia de la Antigüedad Tardía.

Junto a estos epítetos tradicionales se encuentran algunas voces magicae, entre

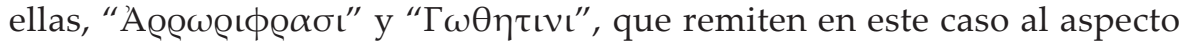

8. Este epíteto en E. Rh. (vv. 530-531) designa a las Pléyades, en tanto que en el $\mathrm{OH} 10$ a las Gracias.

9. Pausanias utiliza $x \theta$ ovía para referirse a Démeter y a su hija (2.35.4.9 y $11 ; 2.14 .5 .3)$.

10. El epíteto XӨovía se aplica a Hécate- Selene en el PGM IV 2550. 
11. El nombre de Perséfone se

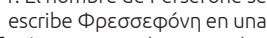
defixión mencionada por Jordan (1985:171). Cfr. Tardieu (2013:235).

12. La traducción es de J. L. Calvo Martínez; M. D. Sánchez Romero (1986).

13. Cfr. Hopfner, 1974-1990:100; Roscher, 1965:VI 763-764.

14. El adjetivo nákap solo modifica a deidades femeninas en E. Bac. 565 y en Hel. 375. También Tardieu 565 y en Hel. 375. También Tardieu
(2013:234) considera que 'Pou $\omega \omega$ sería una deidad femenina, cuyo nombre sería la transcripción de persa medio rwz/rôt 'el día', con la desinencia griega femenina ú.

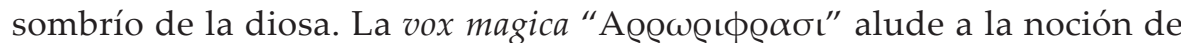
reverencia y de temor religioso, ya que ha sido creada por aliteración de las consonantes y vocales del nombre griego de Afrodita asimilado a Perséfone. ${ }^{11}$ En cambio, " $\Gamma \omega \theta \eta \tau \iota v \iota "$ es considerado una variante de $\Sigma \omega \theta \eta \sigma \iota v \eta$ que funciona como epíteto de Isis, en su aspecto de diosa de sanación (cfr. Tardieu, 2013:235). La mención del nombre bárbaro $\mathrm{B} \alpha \varrho \zeta \alpha \nu$ es otro ejemplo de sincretismo, pero esta vez con el mundo persa. Betz (1986:93), en su edición de los PGM, señala que "the Word BARZA is Persian and means 'shining light'". Además, el nombre B $\alpha \varrho \zeta \alpha$ en PGM XIV a2 es una epíclesis de Helios

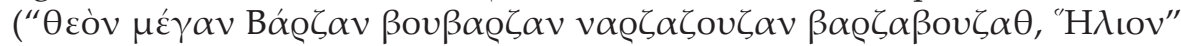
[al dios grande Barzan boubarzan narzazouzan barzabouzath, Helios]). ${ }^{12}$ Es relevante la actuación del 'gran Barza' que se une con Afrodita en una relación amorosa, dado que este vínculo amoroso constituye otra muestra de sincretismo. En la tradición irania el poder fecundante de Anāhitā se complementaba con el de Barza, ya que era quien distribuía el sol que fertiliza la tierra (Tardieu 2013:231).

Otra deidad mencionada que también pertenece al mundo persa es Pov $\zeta \omega$. Merkelbach (1990-1991:764) afirma que Pov $\zeta \omega$ refiere a la Estrella del Norte o el Demonio de una estrella. Betz (1986: 93) $)^{13}$ sostiene que "Rhouzo is confused with the Persian magical word Zouro". También, de acuerdo con Preisendanz (1941) y Roscher (1965:765) sería una deidad masculina, ya que recibe un epíteto masculino ( $\mu \alpha \alpha \kappa \alpha \varrho)$. Sin embargo, $\mu \alpha \alpha \kappa \alpha \varrho$ también puede ser un epíteto de divinidades femeninas, ${ }^{14}$ por lo tanto $\mu \alpha$ $\alpha \alpha \varrho$ en este himno podría alabar a una diosa asimilada con Afrodita. Además, un diosa persa que está relacionada o identificada con Anāhitā recibe como nombre el término Pov $\zeta \omega$ (Tardieu, 2013:236-237).

En este himno la petición aparece fusionada con la eulogia. Además cabe señalar que esta sección característica de los himnos religiosos en los mágicos ocupa un pequeño espacio.

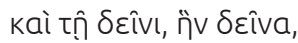

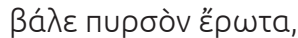

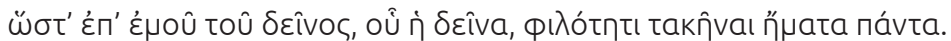

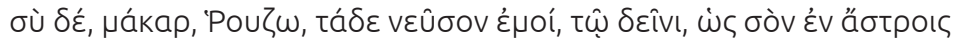

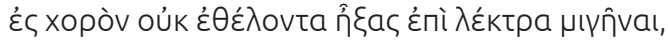

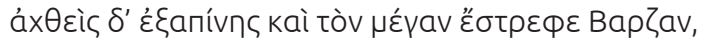

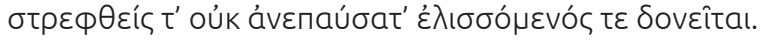

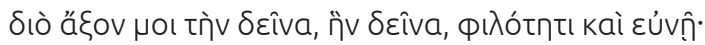

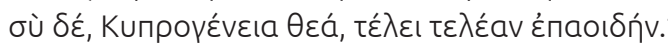

...y a fulana, hija de mengana, infúndele un amor encendido, para que se derrita todos los días de amor por mí, fulano, hijo de fulana. Y tú, Bienaventurado, Ruzo, concédeme esto a mí, fulano, igual que llevaste a tu lecho, para unirte con él, al que no quiera ir a tu coro entre las estrellas; y una vez arrastrado allí, daba vueltas en seguida al gran Barza y no ha dejado de darlas y gira en torbellino ... por esto, trae junto a mí a fulana, hija de mengana, a mi amor y lecho...... Tú, diosa nacida en Chipre, lleva a término el conjuro.

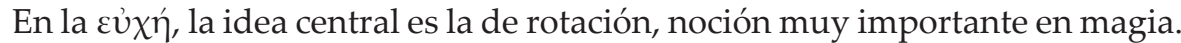
Pero la acción de girar que se atribuye a Pov $\zeta \omega$, puede relacionarse con la estatua cultual de Afrodita en Pafos, donde la diosa es presentada como un pequeño pilar piramidal en torno al cual gira el mundo (cfr. Tac. Hist. 5.3.). Por otra parte, es posible plantear que los giros de la diosa, que logran el 
encadenamiento armonioso con el gran Barza, remiten a la 'rueda ixionia', utensilio que el mago amenazaba emplear contra aquella si no lograba el cumplimiento de su sortilegio.

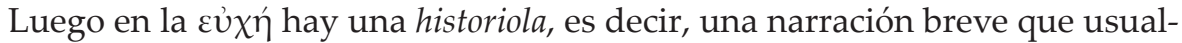
mente evoca historias más extensas que eran bien conocidas. ${ }^{15}$ Cabe señalar además que las historiolae son consideradas como analogías persuasivas, ya que el mago las presenta como el modelo para la acción que desea ejecutar gracias al sortilegio (Iles Johnston, 2004:145). El ambiente imaginado es que Pov $\zeta \omega$ conduce a la víctima a la casa del mago, es decir, la historiola tiene la función de coaccionar al dios. Para confirmar esta interpretación, citamos a Brashear (1995:3439): "The precedent having been cited, the god is obliged to act the same way now as then, this time to the benefit of the conjuror".

El himno se cierra con una nueva invocación a la diosa, donde se le pide que

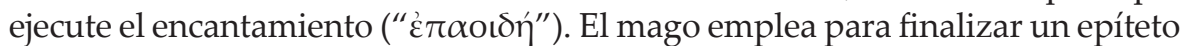

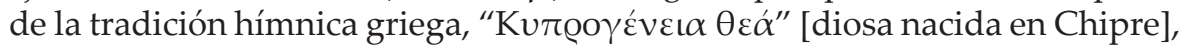
que remite al culto que recibía en Pafos, donde se enfatizaba su participación en los asuntos eróticos (Budin, 2004:111-122).

Resumiendo, el logos de este acto mágico incluye una fórmula de coerción y un

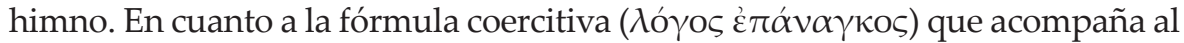
ritual mágico comienza con una breve invocación $(\theta \varepsilon \dot{\varsigma} \varsigma)$ y la petición específica de que la diosa pueda ejecutar rápidamente los deseos del peticionario junto a la amenaza. Posee la forma de una cláusula condicional: si la diosa no cumple con los requisitos del practicante, será privada de su amante, Adonis. El mago lo atará con lazos inconmovibles, por lo que el joven nunca podrá volver del Hades. Las palabras del mago podrían ser llamadas 'maldiciones condicionales' $\mathrm{y}$, entonces se puede afirmar que él hace cosas con sus poderosas palabras, ya que su efectividad se manifiesta al mismo tiempo que el mago las pronuncia. Es posible entonces ver que la eficacia del hechizo depende simultáneamente de la enunciación de la fórmula mágica y del acto ritual (Faraone, 1999:54 n.61).

Por otra parte, se puede sostener que el himno 'mágico', en su estructura y su contenido, no difiere del himno 'religioso'. Como señala Graf (1991:197) los magos y los autores de himnos religiosos usaban versos y fórmulas que provenían de la tradición hímnica. Si bien el himno a Afrodita en el PGM IV se entona mientras se incinera una ofrenda $(\theta v \mu i ́ \alpha \mu \alpha)$, y generalmente los himnos eran cantados en contexto del sacrificio ritual, hay que señalar que difiere el contexto de performance, pues la ejecución pública, compartida por toda la comunidad, ya no es posible por la misma naturaleza secreta de la magia. Una particularidad que distancia al himno mágico de los religiosos es la presencia, en los primeros, de los 'nombres bárbaros' y de las voces magicae, es decir, nombres del dios que solamente conocen unos pocos elegidos. Por esta razón consideramos que su función no es solo forzar a la divinidad sino también demostrar el conocimiento superior del mago. Se consideraba que las deidades se sentían halagadas al ser invocadas por medio de estos nombres secretos. Sin embargo, no queremos negar que la idea de poder coaccionar a los dioses esté ausente en los papiros mágicos, ya que la finalidad de un himno mágico es obligar a la deidad a secundar los propósitos del mago. Lo que pretendemos es señalar que este intento de forzar al dios no constituye una differentia specifica entre la magia y de la religión (Graf, 1991:194), ya que en las fiestas y rituales religiosos tradicionales el conjunto de los fieles también presionan a los dioses para que socorran a la comunidad, aunque en el caso de los himnos y otros rituales de la religión oficial esta presión se basa en la
15. Este elemento está estrechamente relacionado con la tradición hímnica egipcia, como señalan Nagel - Wespi (2015:260): "Fest in der ägyptischen Tradition verankert ist die in Liebes- und anderem Zauber vielfach angewandte Methode der Historiola, in der ein passender Präzedenzfall aus der passender Prazedenzfall aus der
Götterwelt erzählt und so als Form der Hypomnesis (s.o.) in das Ritual eingebunden wird". Por el contrario, Tardieu (2013:237) considera que este himno no posee historiola. 


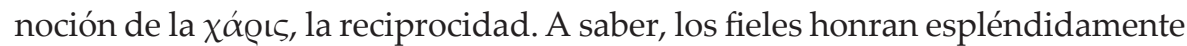
a la deidad, mediante sacrificios, himnos y procesiones; como contrapartida los dioses deben conceder lo que se les solicita.

El análisis del himno a Afrodita en PGM IV (2891-2941), que ha tenido en cuenta muchas características formales, nos permite afirmar que la distinción entre los componentes de naturaleza religiosa y los de naturaleza mágica no es enorme. Sin embargo, la principal diferencia está relacionada con la natu-

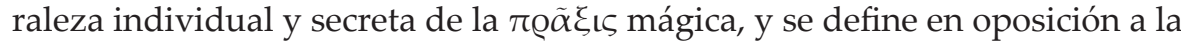
naturaleza colectiva del culto y los rituales en religión pública. 


\section{Q Bibliografía}

» Betz, H. D. (1986). The Greek Magical Papyri in Translation. Including the Demotic Spells. London \& Chicago: The University of Chicago Press.

"Brashear, W. M. (1995). "The Greek Magical Papyri: an Introduction and Survey. Annotated Bibliography (1928-1994)". En: Temporini, H. y Haase, W. (eds.) Aufstieg und Niedergang der Römischen Welt II, 18, 5. Berlin: De Gruyter, 3380-3648.

" Budin, S. L. (2004). "A Reconsideration of the Aphrodite-Ashtart Syncretism", Numen 51.2, 95-145.

»Calvo Martínez, J, L. y Sánchez Romero, M. D. (1986). Textos de Magia en Papiros griegos. Madrid: Gredos.

»Delatte, A. ; Derchain, P. (1964). Les intailles magiques Gréco-Égyptiennes. Paris : Bibliothèque Nationale.

» Dunand, F. (2010). "Culte d' Isis ou religion isiaque?". En : Bricault, L.; Versluys, M. J. (ed.). Isis on the Nile. Egyptian Gods in Hellenistic and Roman Egypt. Liège: Brill, 39-44.

» Faraone, Ch. A. (1999). Ancient Greek Love Magic. London: Harvard University Press.

» Gordon, R. (1999). "'What's in a List?' Listing in Greek and Graeco-Roman malign magical Texts". En: Jordan, D. R.; Montogomery H. y Thomassen E. (eds.). The World of Ancient Magic. Bergen: The Norwegian Institute at Athens, 239-277.

" Graf, F. (1991). "Prayer in Magic and Religious Ritual". En: Faraone, Ch. A.; Obbink, D. (eds.). Magika Hiera. Ancient Greek Magic \& Religion. New York-Oxford: Oxford University Press, 188-213.

» Johnston S. I. (2004); "Magic". En: Johnston S. I. (ed.) Religions of the Ancient World. A Guide. Cambridge: Cambridge University Press, 139-152.

» Jordan, D. R. (1985). "A survey of Greek Defixiones not included in the Special Corpora", GRBS 26, 151-197.

» Karivieri, A. (2010) "Magic and Syncretic Religious Culture in the East". En: Gwynn, D. M.; Bangert, S. (eds.). Religious Diversity in Late Antiquity. Leiden-Boston: Brill, 401434.

» Merkelbach, R. (1990-1991). "Weihrauchopfer und Hymnen an den Planeten Venus und an Hekate (IV 2891-2942)". En: Merkelbach R; Totti M. (eds.). Abrasax. Papyrologica Coloniensia, XVII.1, 2, Opladen: Springer Fachmedien Wiesbaden.

"Nagel, S.; Wespi, F. (2015). "Ägypter, Griechen und Römer im Liebesbann - Antiker ,Liebeszauber' im Wandel der Zeiten“. En: Jördens, A. (ed.), Ägyptische Magie und ihre Umwelt, Philippika 80. Wiesbaden: Harrassowitz Verlag, 218-280.

» Pirenne-Delforge, V. (1994). L'Aphrodite grecque: Contribution à l'étude de ses cultes et de sa personnalité dans le panthéon archaïque et classique. Liège: Kernos.

»Pocceti, P (1991); "Forma e tradizione dell' inno mágico nel mondo classico", A.I.O.N. XIII, 179-204.

»Preisendanz, K. et al. (1928). Papyri Graecae Magicae. Die Griechischen Zauberpapyri, vol. 2. Berlin: Teubner.

" Roscher, W. W. (1965) Ausführliches Lexikon der Griechischen und Römischen Mythologie, vol. 6. Leipzig: Teubner. 
"Simon M. (1980); "Anonymat et Polynymie Divins dans l' Antiquité Tardive". En Perennenitas. Studi in onore di Angelo Brelich. Roma: Edizione dell'Ateneo Roma, 503-520.

» Tardieu, M. (2013). "Les noms magiques d'Aphrodite en déesse barbare (PGM IV 2912-2939)". En: Tardieu, M.; van den Kerchove, A.; Zago, M. (eds.). Noms Barbares I. Formes et contextes d'une pratique magique. Turnhout: Brepols Publishers, 225-238

» Versnel, H. S. (1991), "Some Reflections on the Relationship Magic-Religion", Numen $38.2,177-97$.

» Versnel, H. S. (2002). "The Poetics of the Magical Charm. An Essay in the Power of Words". En: Mirecki, P; Meyer, M. (eds.). Magical Ritual in the Ancient World. Leiden, Boston, Köln: Brill, 105-158.

» Witt, R. E. (1971); Isis in the Graeco-Roman World. London: Thames and Hudson. 